\title{
The Swarmers of Bacillus cereus
}

\author{
By K. A. BISSET AND C. M. F. HALE \\ Department of Bacteriology, University of Birmingham
}

(Received 19 September 1962)

\begin{abstract}
SUMMARY
The production of swarmers by Bacillus cereus occurs naturally, especially in the case of 'mycoides' (i.e. morphologically rough) variants, but can also be induced by growth on media of low nitrogen content containing low concentrations of basic dyes. Very small coccobacilli, usually with one or two polar flagella, are released from the interior of the cells of the mother bacillus. The swarmers are Gram-negative or weakly Gram-positive. On further growth, or on subculture, they increase in size, and may simulate typical Gram-negative bacteria, or in some cases resemble granular, Gram-positive corynebacteria or mycobacteria. Growth of isolated swarmers is extremely slow. On continued subculture, a proportion of strains gradually revert to a Bacillus-like form, complete with heat-resistant endospore. Certain implications of this phenomenon are discussed.
\end{abstract}

\section{INTRODUCTION}

The ability of bacteria to reproduce by a method common to many types of protista, the release of numerous small motile cells, variously described as swarmers and gonidia, has long been known but has been generally ignored. The accepted definition of bacteria (Schizomycetes) embodies the concept that they reproduce only by fission. Beijerinck's description of Rhizobium (1888) describes the phenomenon clearly, if not in detail, but later workers, while admitting the existence of a complex life-cycle, failed to understand the mode of origin of the swarmers, which was first illustrated by Bisset \& Hale (1951), and the similarly, partly recognized phenomenon in Azobacter, by Bisset \& Hale (1953), who pointed out the resemblance. In the case of Spirillum, the occurrence of swarmers has been frequently described; a good illustration was provided by Pease (1956). A general description and illustration of this type of reproduction in bacteria is given by Bisset (1955 a).

The production of swarmers by Bacillus species has often been observed but seldom described in print; although Allen, Appleby \& Wolf (1939) and Appleby (1939) record them in general terms. Our own experiences and numerous personal communications have convinced us that the phenomenon occurs with great frequency, but is usually regarded as evidence of contamination. The present investigation arises from our interest in the problem of the natural relationships of nitrogen-fixing bacteria. These exhibit so many Bacillus-like characters (Bisset, $1952,1955 b)$ that it was considered necessary to determine whether the distinctive character of their swarmer formation was shared by Bacillus; as, in fact, it is. The formation of swarmers and their morphology bear certain interesting inferences, and these are discussed. 


\section{METHODS}

Observations were made on thirty strains of Bacillus cereus isolated in this laboratory. Four of these, including one 'mycoides' variant,"were mainly used and further variants arose in the course of the work. Swarmer production occurred during growth on nutrient agar at $20^{\circ}$, under normal conditions, but was induced by growing the bacteria upon mannitol-nutrient salts medium (Bisset \& Hale, 1953), upon which were laid strips of filter-paper soaked in $0.5 \%(\mathrm{w} / \mathrm{v})$ crystal violet or malachite green. Subcultures were made on nutrient agar, since the growth of this nonnitrogen-fixing species upon the nitrogen-deficient medium was very slight.

\section{RESULTS}

The production of swarmers by Bacillus cereus strains was observed to occur under normal conditions of culture, but irregularly and unpredictably at any age or stage of growth. It was noted, however, that the 'mycoides' variants did so much more freely, and one strain observed produced swarmers consistently on almost every subculture, in sufficient numbers that these could usually be found by a careful search of any film. The appearance of swarmers and mother cells was exactly like that recorded many times for Rhizobium. The 'barred cells' with their thick, basophilic cross-walls, were clearly distinguishable, and so were the broken remnants of cells with emerging swarmers (Pl. 1, figs. 1, 2).

When grown in the presence of basic dyes on filter-paper strips, the results were very similar to those produced by penicillin used in a similar way. A variable area, 5-15 mm. wide, around the strip, produced no visible growth. In an intermediate zone of similar size, where L-forms might be expected in the analogous instance, was a thin irregular growth consisting mainly of organisms in the process of producing swarmers. Beyond this zone, growth was normal. By this means, both 'cereus' and 'mycoides' variants were induced to produce swarmers freely (Pl. 1, figs. 3, 4). The swarmers were of variable size, some being relatively long and slender and staining in a granular fashion that gave them a rather surprising resemblance to corynebacteria or mycobacteria (Pl. 1, figs. 5, 6). Characteristically, however, the swarmers were small Gram-negative coccobacilli, motile by means of one or two polar flagella (Pl. 1, fig. 7), and exactly resembling the swarmers of Rhizobium and Azotobacter (Bisset \& Hale, 1951, 1953).

It is considered that the possibility of swarmers of this type being contaminants is obviated by the facts, first that their actual production could be observed, and secondly that nothing of the sort appeared upon control plates, either uninoculated or inoculated with 'subtilis'-type bacilli, which did not, in our experience, behave in this manner.

The growth of the cultures upon nitrogen-deficient medium was exceedingly slight, but on subculture on nutrient agar the swarmers could be isolated. Their growth and development was at first very slow, even on this medium, on which the parent strains grew freely. After several weeks of subculture, growth improved and the swarmers followed a fairly standard cycle of increase in size and gradual reversion to the staining reactions and morphology of the original bacilli. Endospores began to appear while size was still reduced, and Gram-positivity weak or 
absent. Restoration of flagellar pattern was of interest. One strain, almost immediately on subculture from the swarmer stage, while still small, slender and asporogenous, produced a large number of peritrichous flagella, whereby it was able to swarm very actively on a moist agar plate (PI. 2, fig. 8). In three other strains, as size increased, the flagella, while remaining few in number, became changed in position from a polar to a lateral position (Pl. 2, figs. 9, 10).

The last character to be regained in the strains examined was the original cultural appearance; and the revived strains, after several months of subculture, tended to be rather feeble by comparison with the originals. Such revivals of the original morphology were achieved by selection and subculture of progressively larger, more Gram-positive variants from the cultures of swarmers at various stages, except in the case of the first very tiny swarmers, which rarely retained this form for more than a single subculture, but rapidly increased in size. Beyond this point, it was possible to obtain fairly stable variants of the general appearance of Gramnegative, coliform bacteria.

\section{DISCUSSION}

From these observations of swarmer production in Bacillus cereus strains under normal conditions of culture and when induced to do so by the presence of basic dyes, several interesting points arise. It is apparent that the relatively well-known reproduction of the nitrogen-fixing bacteria, especially Rhizobium, in this manner, is in complete accordance with the theory that these bacteria are closely related to the Bacillaceae. Even in such details as the barred appearance of the mother cells and the formation of relatively stable Bacterium-like variants from the tiny swarmers, they are exactly alike.

Further observations relative to the problem of phylogenetic relationships in bacteria arise from the appearance of the swarmers themselves, which are capable of simulating closely certain of the smaller Gram-positive and Gram-negative bacterial genera. The hypothesis has recently been proposed (Bisset, 1962) that the ancestral type of terrestrial bacterium was probably a form of Bacillus; and this concept is supported by the conclusion, drawn from electrically computed taxonomy, that Bacillus appears to be more closely related to certain Gram-negative genera than is any other Gram-positive genus (Sneath \& Cowan, 1958). The observations reported in the present paper suggest one route whereby evolution might have occurred, through a process resembling neoteny. In this context, the claims of Csillag (1961) to have established a relationship between Bacillus and Mucobacterium are of interest, in view of the mycobacterial morphology of some of the swarmers of Bacillus cereus here illustrated. The hypothetically primitive condition of Bacillus is also confirmed by this retention of the power to produce swarmers, a character that is commonly found, among bacteria, only in the spirilla, which give evidence of linking the bacteria with other flagellate protista, where such swarmers are a commonplace (cf. Bisset, 1962). In more specialized bacteria this power has apparently been lost, together with other elaborate characters appertaining to their free-living ancestors.

Lastly, the phenomena of swarmer-production bear certain resemblances to the L-cycle (cf. Pease, 1956) which also occurs, at least upon occasion, by the intervention of a filamentous rough phase (Pease, 1962). True L-formation is unusual 
in Bacillus, and penicillin has no such effect, in our experience, nor does it induce the formation of swarmers. There is, nevertheless, a distinct resemblance to penicillin in the action of the basic dyes described here, since both appear to act mainly upon the cell envelopes of Gram-positive bacteria. The large bodies of L-forms are now generally regarded as bacterial protoplasts that have discarded the cell wall, either by genetic accident or to avoid the action of penicillin (Pease, 1957). It is possible that the small bodies may represent a degenerate relict of swarmer production, and be simply a smaller grade of protoplast.

\section{REFERENCES}

Aluen, L. A., Appleby, J. C. \& Wolf, J. (1939). Cytological appearances in a sporeforming bacillus. Evidence of Meiosis. Z Zbl. Bakt. (Abt. II), 100, 3.

Appleby, J. C. (1939). The production and characters of a small rod variant of a sporeforming Bacillus. Zbl. Bakt. (Abt. II), 101, 41.

Beijerinck, M. W. (1888). Die Bakterien der Papilionaceenknöllchen. Botan. Zeit., 46, 725. (Translated in Brock, T. D., Milestones in Microbiology, 1961. London: Prentice-Hall Int. Inc.).

Bisset, K. A. (1952). Complete and reduced life cycles in Rhizobium. J. gen. Microbiol. 7, 233.

BISSET, K. A. (1955 a). The Cytology and Life-History of Bacteria. Edinburgh : Livingstone.

Bisset, K. A. (1955 b). Evidence from the cytology of Azotobacter chroococcum of a relationship with Rhizobium and the Bacillaceae. J. gen. Microbiol. 13, 442.

Brsser, K. A. (1962). The phylogenetic concept in bacterial taxonomy. In Symp. Soc. gen. Microbiol. 12, 361.

Bisset, K. A. \& HaLe, C. M. F. (1951). The production of swarmers in Rhizobium spp. J. gen. Microbiol. 5, 592.

Bisset, K. A. \& Hale, C. M. F. (1953). The cytology and life-cycle of Azotobacter chroococcum. J. gen. Microbiol. 8, 442.

Csillag, A. (1961). Spore-formation and 'dimorphism' in the Mycobacteria. J. gen. Microbiol. 26, 97.

Pease, P. E. (1956). The gonidial stages in Spirillum spp. and Vibrio spp. J. gen. Microbiol. 14, 672 .

Pease, P. E. (1957). The electron microscopy of L-forms induced by penicillin in Proteus vulgaris. J. gen. Microbiol. 17, 64.

PEASE, P. E. (1962). Evidence that Streptobacillus moniliformis is an intermediate stage between a corynebacterium and its L-form or derived PPLO. J. gen. Microbiol. 29, 91.

Sneath, P. H. A. \& Cowan, S. T. (1958). An electro-taxonomic survey of bacteria. J. gen. Microbiol. 19, 551.

\section{EXPlanation OF PLATES}

\section{Plate 1}

Figs. 1, 2. Barred mother cells and swarmers. Basic fuchsin. Photomicrographs. $\times \mathbf{2 5 0 0}$.

Figs. 3, 4. Mother cells and swarmers produced by exposure to crystal violet. Electron micrograph, gold-palladium shadowed. $\times 20,000$ and 5000, respectively.

Figs. 5, 6. Mother cells and swarmers of 'mycoides' variant, the swarmers resembling corynebacteria. (5) Electron micrograph, gold-palladium shadowed. $\times 7000 .(6)$ Photomicrograph, basic fuchsin. $\times \mathbf{3 0 0 0}$.

Fig. 7. Swarmer showing two polar flagella. Electron micrograph, gold-palladium shadowed. $\times 5000$.

\section{Plate 2}

Fig. 8. Enlarged swarmer of unusual type, subcultured upon nutrient agar, showing numerous peritrichous flagella. Electron micrograph, gold-palladium shadowed. $\times 20,000$.

Figs. 9, 10. Stages in the recovery of peritrichous flagellation and Bacillus-like morphology. Electron micrographs, gold-palladium shadowed. $(9) \times 20,000 ;(10) \times 10,000$. 


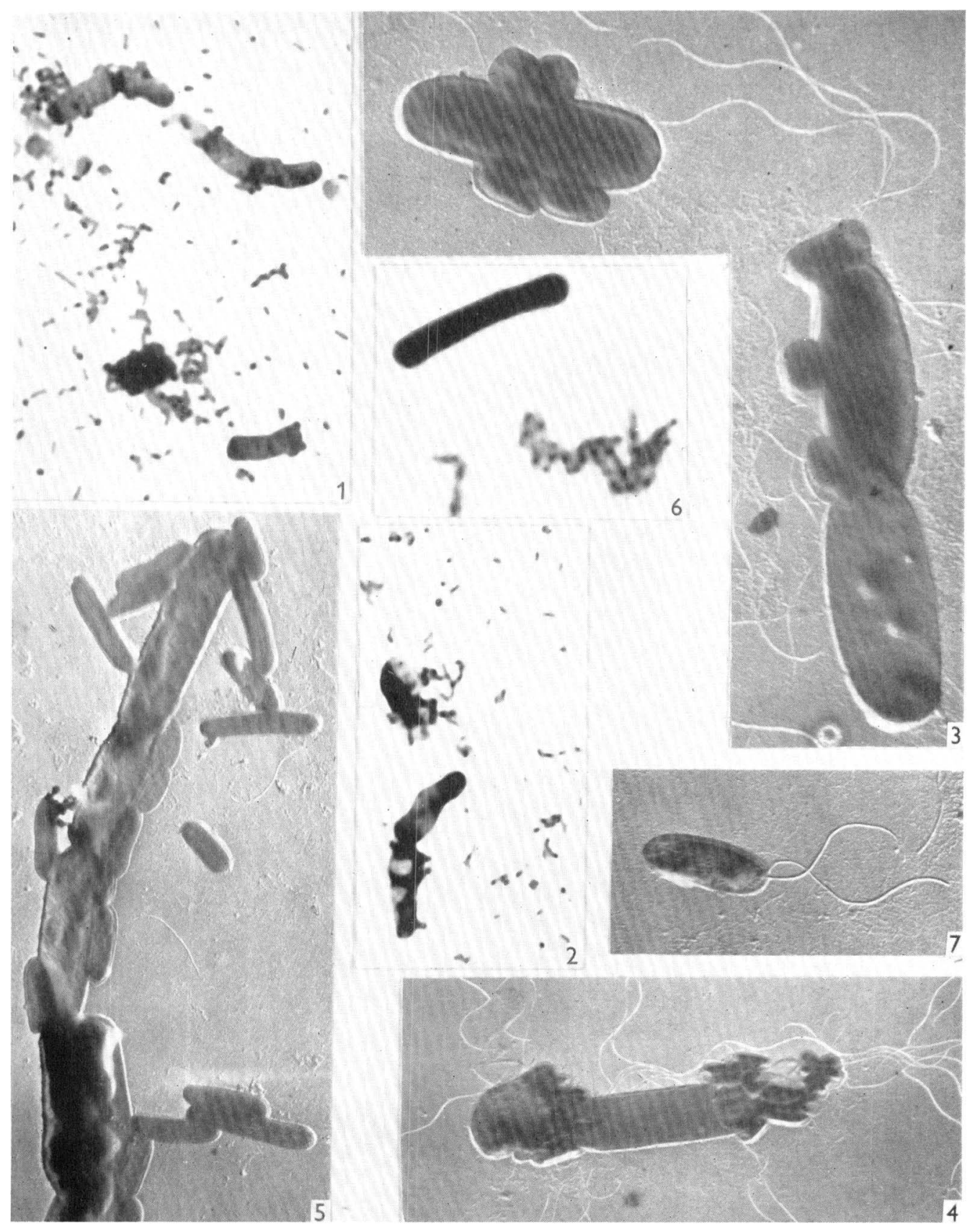



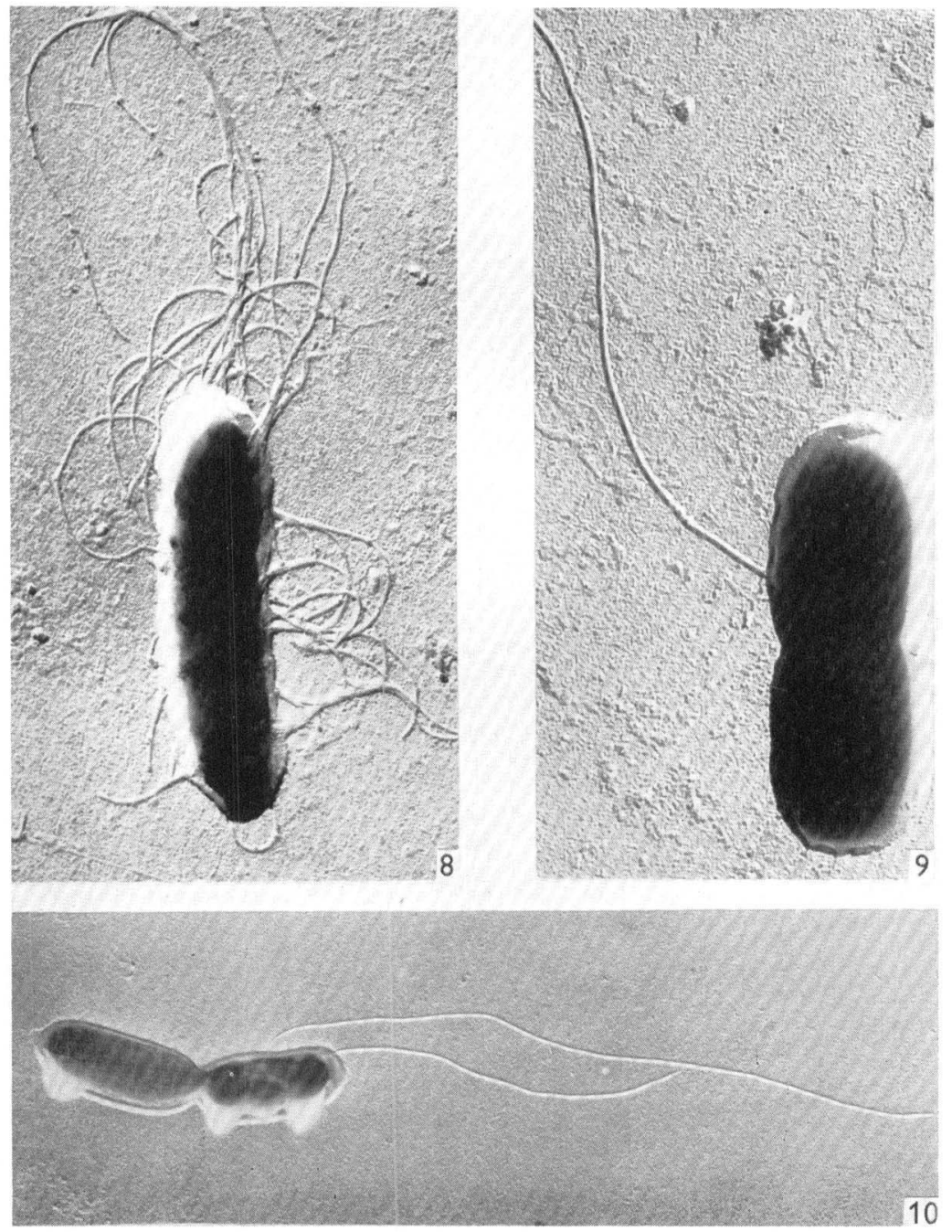

K. A. BISSET AND C. M. F. HALE 